This item was submitted to Loughborough's Research Repository by the author.

Items in Figshare are protected by copyright, with all rights reserved, unless otherwise indicated.

\title{
Expansions with different origins in a concrete dam with bridge over spillway
}

PLEASE CITE THE PUBLISHED VERSION

https://doi.org/10.1016/j.conbuildmat.2017.12.161

\section{PUBLISHER}

(c) Elsevier

\section{VERSION}

AM (Accepted Manuscript)

\section{PUBLISHER STATEMENT}

This work is made available according to the conditions of the Creative Commons Attribution-NonCommercialNoDerivatives 4.0 International (CC BY-NC-ND 4.0) licence. Full details of this licence are available at: https://creativecommons.org/licenses/by-nc-nd/4.0/

\section{LICENCE}

CC BY-NC-ND 4.0

\section{REPOSITORY RECORD}

Blanco-Alvarez, Ana, Sergio Pialarissi-Cavalaro, Ignacio Segura, Luis Segura-Castillo, and Antonio Aguado. 2018. "Expansions with Different Origins in a Concrete Dam with Bridge over Spillway". Loughborough University. https://hdl.handle.net/2134/32283. 


\title{
Expansions with different origins in a concrete dam with bridge over spillway
}

\author{
A. Blanco*1, S. H.P. Cavalaro ${ }^{1}$, I. Segura ${ }^{2,3}$, L. Segura-Castillo ${ }^{4}$, A. Aguado ${ }^{2}$ \\ ${ }^{1}$ School of Architecture, Building and Civil Engineering, Loughborough University, Epinal Way, Loughborough \\ LE11 3TU, United Kingdom \\ ${ }^{2}$ Dept. of Civil and Environmental Engineering, Universitat Politècnica de Catalunya-BarcelonaTech, Jordi Girona 1- \\ 3, Building C1-202, 08034 Barcelona, Spain \\ ${ }^{3}$ SMART ENGINEERING SL, Jordi Girona 1-3, Parc UPC K2M, 202c, 08034 Barcelona, Spain \\ ${ }^{4}$ Insituto de Estructuras y Transportes, Facultad de Ingeniería, Universidad de la República, Julio Herrera y Reissig \\ 565, 11300 Montevideo, Uruguay. \\ * Corresponding author: a.blanco-alvarez@lboro.ac.uk
}

\begin{abstract}
Concrete dams with expansions from different origins are rare and scarcely documented in the literature, therefore their study gains special interest. This study presents the case of a 62-year-old concrete dam with signs of deterioration due to expansive reactions. Several tests performed on the samples extracted from the dam such as X-ray diffraction, scanning electron microscope with energy dispersive spectroscopy mode and petrography suggest that the expansions are due to a delayed ettringite formation and a subsequent alkali-silica reaction. Thermal and mechanical models developed in the study support this diagnosis.
\end{abstract}

Keywords: gravity dam, expansions, alkali-silica reaction, delayed ettringite formation, modelling

\section{INTRODUCTION}

Concrete dams are massive structures that may be subjected to different processes of deterioration, including expansions, that affect its structural behavior. Often, the source of the damage cannot be explained by a single phenomenon. The diagnosis and evaluation of the concrete dam in such scenario gains special relevance given the scarce number of cases reported in the literature.

In terms of expansive reactions, the most common is the alkali-silica reaction (ASR), which has been extensively studied (Stanton 1942; Hobbs 1988; Zhang et al. 2009; Ramyar et al. 2005; Na et al. 2016). Less common are the internal sulfate attack (ISA), despite several studies conducted in the past years (Chinchón et al., 1995; Ayora et al., 1998; Schmidt et al. 2009; Oliveira et al., 2013a; Oliveira et al., 2013b; Oliveira et al., 2014; Chinchón-Payá et al., 2015, Rodrigues et al. 2015; Rodrigues et al., 2016) and the alkali-carbonate reaction (ACR) (Grattan-Bellew and Chan, 2013; Stukovnik et al., 2014, Blanco et al., 2016, Sanchez et al. 2017).

Beside the above reactions, another type of internal sulfate attack may occur that it is not caused by the presence of sulfates in the aggregates, known as delayed ettringite formation (DEF). It occurs when the temperature during construction and curing exceeds $70^{\circ} \mathrm{C}$. DEF may be defined as the formation of ettringite (secondary ettringite) in a hardened material stored in wet conditions and without any external sulfate source, resulting in swelling (Scrivener and Taylor 1993; Diamond 1996; Taylor et al. 2001).

Roxburgh dam in New Zealand is the first case reported in the literature with an unusual ettringite content associated to DEF (Kennerly 1965). Recently, another case was reported in Vrané nad Vltavou dam constructed between 1930-1936 in Czech Republic (Šachlová et al., 2014).

This paper aims at presenting a conclusive diagnosis for a gravity dam with evident signs of degradation due to expansive reactions. The hypothesis, formulated after analyzing the state of the dam and reviewing the scarce historical documents available, consists in the combined effect of a DEF occurring short after the construction and a subsequent ASR. In order to validate such hypothesis, microstructural analyses on mortar and aggregate samples were performed as well as 
models to assess the evolution of temperature during the construction of the dam and the expansion in the spillway.

The relevance of this paper lies in the singularity of the case study, where two expansions of different origins occurred in the same concrete dam. Additional interest may come from the lack of monitoring and limited historical documentation, which hinders the diagnosis. In this context, the study may serve as a valuable example for future diagnosis of concrete dams.

\section{DESCRIPTION OF THE DAM}

\subsection{General characteristics}

This gravity dam was built in 1955 for water supply. It consists in a plain concrete Creager spillway of $100 \mathrm{~m}$ of length and a maximum height from the foundations of $14.0 \mathrm{~m}$. The spillway is divided into concrete blocks of $15.0 \mathrm{~m}$ of width, with the exception of the central block that is $7.1 \mathrm{~m}$ wide. The concrete spillway provides support to the diaphragms of a reinforced concrete slab road bridge that crosses the river (see Fig. 1).

The slab is $0.39 \mathrm{~m}$ thick and it is divided in three parts: a central part $7.10 \mathrm{~m}$ long and two continuous parts supported every $5.0 \mathrm{~m}$. The diaphragms are $0.35 \mathrm{~m}$ thick with the exception of the ones supporting the central part which are $0.40 \mathrm{~m}$. The control valves are accessible from the road by means of a concrete stairway located at the central span of the bridge.

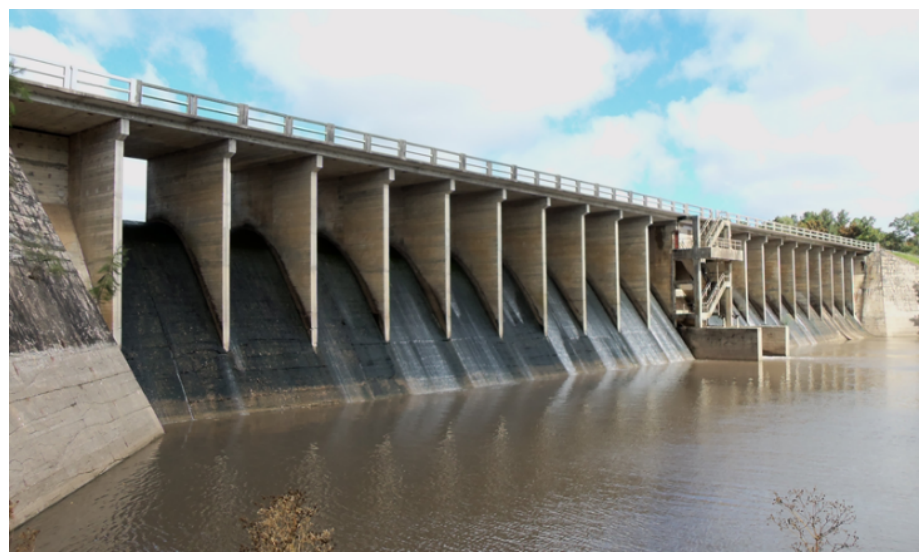

Fig. 1 General view of the concrete dam and the bridge over the spillway.

Consolidated soil dikes with lengths of $451 \mathrm{~m}$ on the left side and $231 \mathrm{~m}$ on the right side provide access to the bridge. The width of the dikes is $61.3 \mathrm{~m}$ at the base and $9.8 \mathrm{~m}$ at the crest. Unreinforced concrete retaining walls contain the dikes.

\subsection{Construction and materials}

The documents related to the design and construction of the dam include descriptive report of the original project and the construction plans dating from the early 1950s. The information regarding the construction procedure is not extensive, however specifications are given for the pouring of the concrete, the joints and the curing.

Specifically, it is mentioned that the concrete will not be poured at a temperature lower than $5^{\circ} \mathrm{C}$ or higher than $28{ }^{\circ} \mathrm{C}$. Likewise, the concrete layers between contraction joints will not exceed 30 $\mathrm{cm}$ with a maximum progress of $1.5 \mathrm{~m}$. The exposed surface, which will maintain a rough texture to ensure bond with the subsequent layer, will be protected from the sunlight at least during 3 days after the pouring. In addition, the concrete will be wetted during the following 3 weeks. The 
document also includes recommendations regarding the joints between two layers of concrete and between concrete and rock.

In terms of concrete mix and its components, the information is not sufficiently accurate. The only reference to the type of cement is in the tender specifications of the project, where it is stated: "the Portland cement will be of slow setting. Cement that was previously stored will not be employed". Despite the above, there is no certainty that this type of cement was used in the construction of the dam since no records from the construction period are available. Furthermore, it is known that slow setting cements were first introduced in the country for the construction of another concrete dam in 1974. These uncertainties regarding the origin and type of cement represent a drawback in the diagnosis given that the amount of gypsum, alumina phases $\left(\mathrm{C}_{3} \mathrm{~A}\right)$ and alkali in the cement is unknown.

In terms of the operation and management period, the historical documents indicate that horizontal cracking in the spillway appeared shortly after the construction since repair and maintenance operations were already conducted in the decade of the 1960s. In addition, the dam is not monitored and thus no records are available of the evolution of displacements through the years

\section{CURRENT STATE OF THE DAM}

The current state of the dam will be described according to the main elements of the structure: the spillway (including the structure of the stairway), the bridge and the dikes. Table 1 presents a summary of the main evidences of damage found in the visual inspection of the dam.

The spillway presents horizontal cracks in the upstream and downstream faces that develop along the planes of the construction or filling joints. These cracks were reported in studies dating from 1989 and 1996 and were described as non-continuous (the downstream face was dry and were no signs of infiltrations).

Table 1. Evidences of damage in the main elements of the dam.

\begin{tabular}{|c|c|c|}
\hline Element & Location & $\begin{array}{l}\text { Description of damage } \\
\end{array}$ \\
\hline \multirow{3}{*}{ Spillway } & Downstream face & Horizontal cracks without signs of infiltration \\
\hline & Upstream face & Horizontal cracks \\
\hline & Structure of stairway & $\begin{array}{l}\text { Loss of concrete cover, corrosion and } \\
\text { deformation of the reinforcement }\end{array}$ \\
\hline \multirow[b]{2}{*}{ Bridge } & Deck & No signs of severe damage \\
\hline & Diaphragms & $\begin{array}{l}\text { Surface erosion, corrosion of reinforcement } \\
\text { and cracking }\end{array}$ \\
\hline Dikes & Retaining walls & Map cracking \\
\hline
\end{tabular}

Fig. 2 shows the horizontal cracks in the downstream face. Some of the gate mechanisms, hanging from the central blocks of the spillway are detached from the concrete due to a certain rotation between the upper and bottom part of the blocks. This rotation is consistent with the presence of horizontal cracks in the construction joints. 

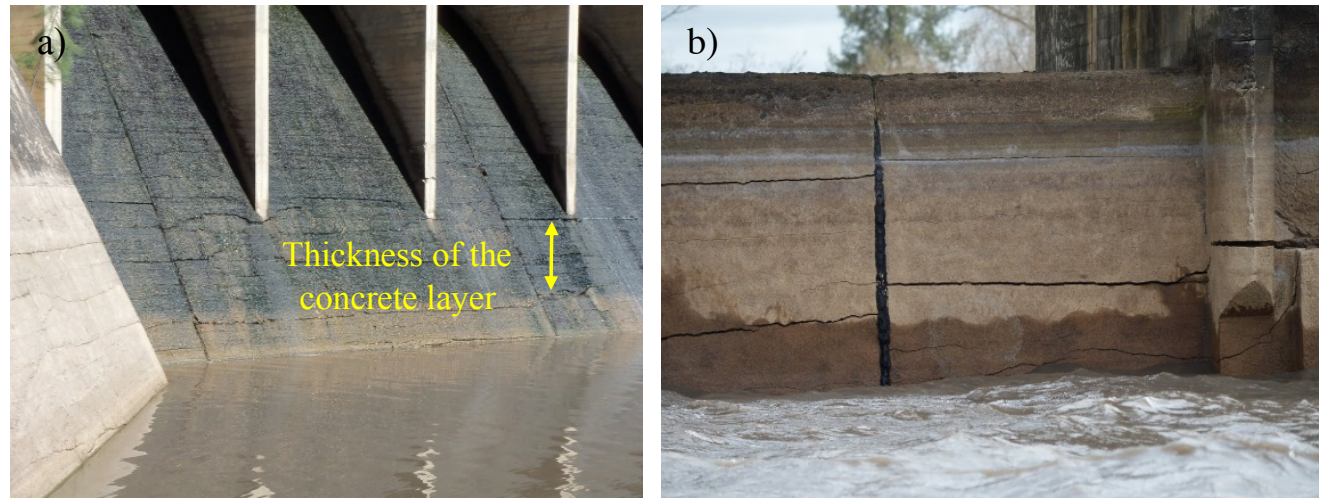

Fig. 2 Horizontal cracks in: a) the downstream face and b) upstream face.

The structure of the stairway exhibits several signs of degradation of the concrete in the columns and the walls of the structure, such as loss of concrete cover in certain areas and corrosion of the reinforcement. The deck of the bridge is not severely damaged, some cracks were detected in the lower surface of the deck, perpendicular to its axis, that may correspond to cold joints. In the central block of the spillway, the deck is supported on two rocker bearing beams, one of which exhibits a certain rotation. The connection with the diaphragms consists in 20 rebars per pile with a diameter of $19 \mathrm{~mm}$. The diaphragms of the bridge present signs of degradation of different sort, including erosion of the surface (see Fig. 4a), corrosion of the reinforcement and cracking.
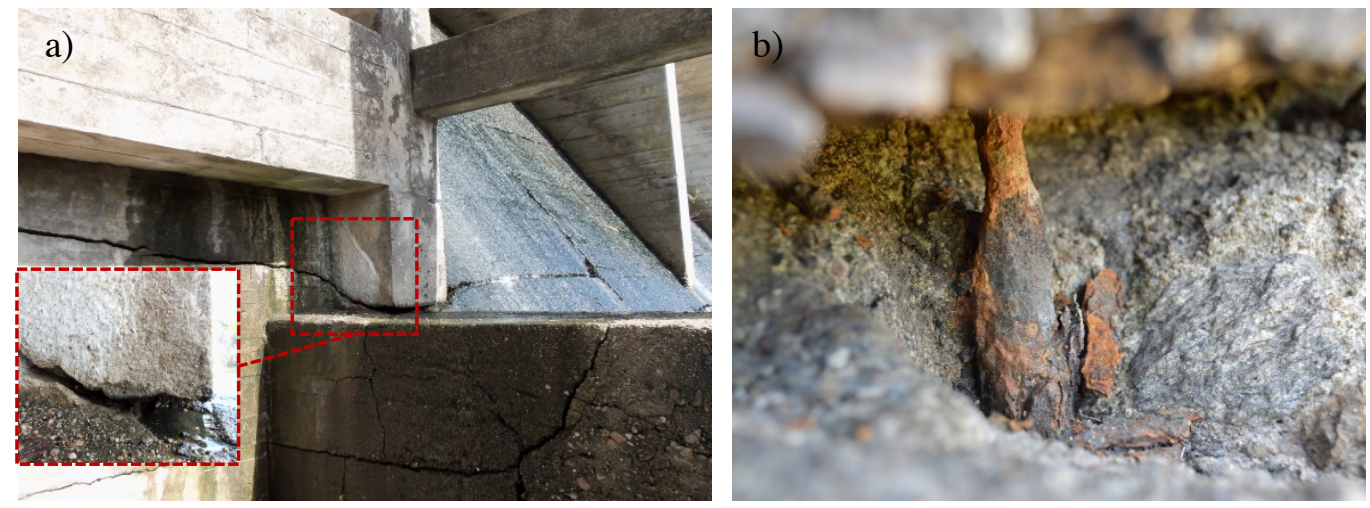

Fig. 3 Structure of the stairway: a) cracks and loss of concrete and b) corrosion of the rebars.
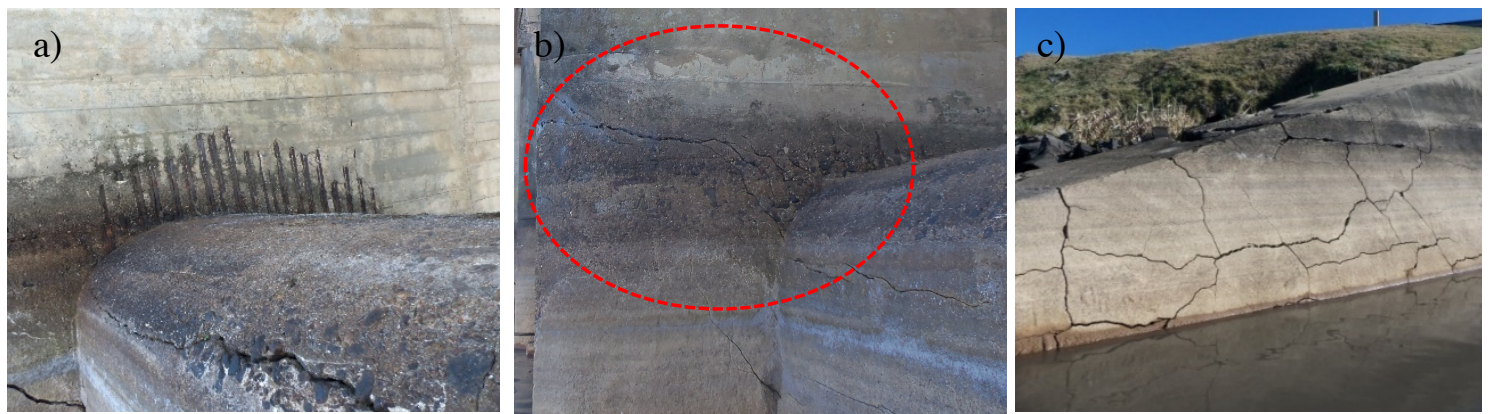

Fig. 4 a) Erosion in diaphragms with visible rebars, b) cracks in diaphragms developing from the contact with the spillway and c) map cracking in the retaining walls of the dike.

Fig. $4 \mathrm{~b}$ shows cracks that develop perpendicularly to the contact area with the spillway and develop to the pile. The diaphragms present a construction joint in their axis that is also cracked. Vertical cracks induced by the corrosion of the reinforcement are also detected in some of the 
diaphragms. The retaining walls of the dikes exhibit map cracking in the upstream face (see Fig. $4 c)$ and both horizontal cracks and map cracking in the downstream face.

\section{MATERIALS AND METHODS}

\subsection{Materials}

The microstructural analyses were conducted on aggregate samples from the quarry located near the dam and on mortar samples obtained from concrete cores. Seven cores were drilled from different elements of the dam in September 2015 (including the spillway, the retaining walls, the stairway structure and the diaphragms of the bridge). Table 2 presents details of the notation of the cores, location, dimensions and mechanical properties. The mechanical tests were performed according to the standard UNIT-NM 69:1998 (UNIT 1998). The compression test was subsequently corrected according to ACI 214R-11 (ACI 2011) (Centragolo et al. 2016).

Table 2. Details of the cores.

\begin{tabular}{cccccc}
\hline Notation & Location & $\begin{array}{c}\text { Diameter } \\
(\mathbf{m m})\end{array}$ & $\begin{array}{c}\text { Length } \\
\mathbf{( m m )}\end{array}$ & $\begin{array}{c}\text { Compressive } \\
\text { strength (MPa) }\end{array}$ & $\begin{array}{c}\text { Elastic } \\
\text { modulus (GPa) }\end{array}$ \\
\hline M1 & Wall in stairway structure & 93.4 & 170 & 32.7 & - \\
\hline P1 & Diaphragm of bridge & 93.5 & 250 & 29.7 & 18.7 \\
\hline P2 & Diaphragm of bridge & 73.5 & 180 & 29.8 & - \\
\hline T1 & Retaining wall & 93.0 & 350 & 30.8 & 12.4 \\
T2 & Retaining wall & 93.2 & 350 & 28.3 & 13.4 \\
\hline V1 & Spillway & 93.5 & 850 & 14.9 & 7.4 \\
\hline V2 & Spillway & 99.3 & 750 & 22.8 & 15.4 \\
\hline
\end{tabular}

Mortar samples were extracted for Scanning Electronic Microscopy (SEM) and X-Ray Diffraction (XRD) analyses from locations that presented cracks in the cement paste or aggregate, precipitates in vacuoles, reaction rims on the aggregates, etc., as well as from unaltered zones. Furthermore, aggregates were taken from the concrete samples to be analyzed with the aggregates collected near the dam.
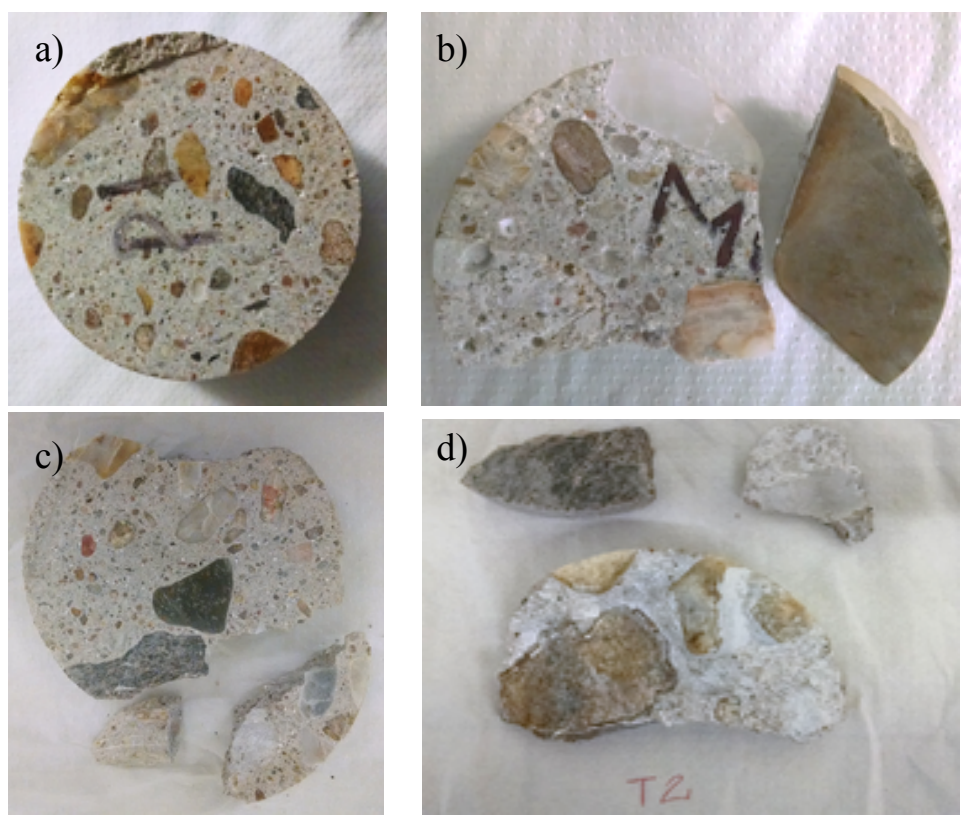

Fig. 5 Concrete samples obtained from the drilled cores: a) P1, b) M1, c) T1 and d) T2. 


\subsection{Evaluation methods: microstructural characterization}

Different microstructural techniques were used to characterize both the aggregates and the concrete samples. On the one hand, the analyses performed on the aggregate samples allowed identifying their main characteristics and their potential reactivity against ASR. On the other hand, the assessment of the concrete samples provides insight into the possible degradation phenomena. XRD analyses and petrographic examination of selected thin sections were conducted after proper preparation of the aggregate samples as well as physical tests. Furthermore, the mortar samples were also analyzed by XRD and SEM.

The XRD samples were grinded and sieved through a $0.063 \mathrm{~mm}$ sieve to eliminate large aggregate particles. XRD analyses were made in a PANalytical X'Pert PRO MPD Ө/Ө diffractometer of $240 \mathrm{~mm}$ of radius in a configuration of convergent beam with a focalizing mirror and transmission geometry. CuKa radiation $(\mathrm{k}=1.5418 \AA)$ and PIXcel detector with active length of $3.347^{\circ}$ were used. Work power was set to $45 \mathrm{kV}-40 \mathrm{~mA}$. $2 \Theta / \Theta$ scans from 4 to $80^{\circ} 2 \Theta$ with a step size of $0.026^{\circ} 2 \Theta$ and a measuring time of $200 \mathrm{~s}$ per step were performed. Qualitative phase identification was made with X'Pert High Score Plus and the crystallographic database PDF-2 from ICDD. The main crystallographic phases and their corresponding PDF files are shown in Table 3.

Table 3. Crystalline phases identified in the XRD measurements

\begin{tabular}{ccc}
\hline Phase & Formula & PDF file \\
\hline Quartz & $\mathrm{SiO}_{2}$ & $01-086-1560$ \\
Microcline & $\mathrm{K}\left(\mathrm{AlSi}_{3} \mathrm{O}_{8}\right)$ & $01-076-1239$ \\
\hline Albite & $\mathrm{Na}\left(\mathrm{AlSi}_{3} \mathrm{O}_{8}\right)$ & $01-076-0898$ \\
\hline Muscovite & $\mathrm{KAl}_{2}\left(\mathrm{AlSi}_{3} \mathrm{O}_{10}\right)(\mathrm{OH})_{2}$ & $01-089-5401$ \\
\hline Calcite & $\mathrm{CaCO}_{3}$ & $083-0577$ \\
\hline Portlandite & $\mathrm{Ca}(\mathrm{OH})_{2}$ & $072-0156$ \\
\hline Ettringite & $\mathrm{Ca}_{6} \mathrm{Al}_{2}\left(\mathrm{SO}_{4}\right)_{3}(\mathrm{OH})_{12} \cdot 26 \mathrm{H}_{2} \mathrm{O}$ & $041-1451$ \\
\hline & & $050-1607$ \\
Monosulphoaluminate & $3 \mathrm{CaO} \cdot \mathrm{Al}_{2} \mathrm{O}_{3} \cdot \mathrm{CaSO}_{4} \cdot 12 \mathrm{H}_{2} \mathrm{O}$ & $031-0245$ \\
& & $033-0256$ \\
\hline Hydrogarnet & $3 \mathrm{CaO} \cdot \mathrm{Al}_{2} \mathrm{O}_{3} \cdot\left(\mathrm{SO}_{4}\right) \cdot 6 \mathrm{H}_{2} \mathrm{O}$ & $084-0917$ \\
\hline
\end{tabular}

SEM studies were performed in a SEM Jeol J-6510 electronic microscope with EDX and backscattered electron detectors. Before the samples were metalized, their size was reduced to fit the holders. An operating voltage of $22 \mathrm{kV}$ was used for all the analyses. The petrographic studies were conducted after selecting some of the samples based on the results of the XRD. An optical microscope with polarized light was used for that purpose.

\subsection{Evaluation methods: thermal modelling}

The horizontal cracks in the spillway may have been caused by thermal effects or due to an expansive reaction due to high temperatures in the concrete. The thermal modelling simulates the construction the dam and the different processes of thermal interchange and the heat generation through a finite differences approach. The outcome includes the evolution of the internal temperature of the concrete as well as the temperature at the surface, thus identifying whether $70^{\circ} \mathrm{C}$ was exceeded at some point of the dam.

\subsubsection{Basic considerations on heat transfer}

The thermal behavior of the dam involves other phenomena besides the heat generated by the cement hydration, namely the heat transfers due to convection, radiation and thermal diffusion. 
The two formers occur in the interface between the concrete and the environment, whereas the latter is internal.

The heat release during the cement hydration is assumed to increase exponentially according to the Eq. (1), which is defined considering typical curves of heat release. The parameters of the equation are the energy released per cubic meter of concrete $\left(Q_{H}\right)$ in a certain time $(t)$, the maximum heat released per kilogram of cement $\left(q_{H, \max }\right)$, the cement content in $\mathrm{kg}$ per cubic meter of concrete $\left(m_{c}\right)$ and a constant that governs the cement hydration kinetics $(a)$, with high values for fast hydration cements and low values for slow hydration cements.

$$
Q_{H}=q_{H, \max } \cdot m_{c} \cdot\left(1-e^{-a \cdot t}\right)
$$

The heat transfer due to convection occurs when the atmospheric air warms up due to the higher temperature of the surface of the dam. The warm air reduces its density and its driven away by new air volumes at lower temperatures that contact the concrete surface. This phenomenon takes place successively until thermal equilibrium with the environment is reached. The heat variation in concrete due to the described phenomenon $\left(d Q_{C}\right)$ per small time intervals $(d t)$ of an infinitesimal concrete element located in the downstream surface of the dam $(d A)$ is governed by Eq. (2). In this equation, $h$ is the convection coefficient, $T_{h}$ is the superficial temperature of concrete in a certain point and $T_{a}$ is the ambient temperature.

$$
\frac{\partial Q_{C}}{\partial t}=h \cdot d A \cdot\left(T_{h}-T_{a}\right)
$$

The difference of temperature between the concrete surface and the environment generates a second heat transfer known as radiation, which consists in the emission of thermal radiation that contributes to cool the concrete. The estimate of superficial energy loss in the concrete due to the thermal radiation $\left(d Q_{R}\right)$ per differential area $(d A)$ and differential time $(d t)$ is calculated according to Eq. (3). The parameter $\epsilon$ is the concrete emissivity and $\sigma$ is the Stefann-Boltzmann constant that equals $5,7 \times 10-8 . \mathrm{W} \cdot \mathrm{m}^{-2} \cdot \mathrm{K}^{-4}$.

$$
\frac{\partial Q_{R}}{\partial t}=\epsilon \cdot \sigma \cdot d A \cdot\left(T_{H}{ }^{4}-T_{a}{ }^{4}\right)
$$

Since the temperature inside the dam is not uniform, other heat transfers must occur among different points in the concrete mass. Due to the heat release from the cement hydration and the heat transfer with the environment, the early age concrete exhibits a non-stationary temperature profile. Assuming such non-stationary condition, the heat transfer in each point is governed by Fick's second law that represents the Cartesian three-dimensional space (see Eq. (4)). In this equation, $Q_{d}$ represents the amount of heat in a certain point and $D$ is the heat diffusion coefficient in concrete.

$$
\frac{\partial Q_{D}}{\partial t}=D \cdot\left(\frac{\partial^{2} Q_{D}}{\partial x^{2}}+\frac{\partial^{2} Q_{D}}{\partial y^{2}}+\frac{\partial^{2} Q_{D}}{\partial z^{2}}\right)
$$

The total heat variation $(d Q)$ with time in a certain point located at the surface of the dam and the point located inside the dam may be represented by the previous equation, as indicated in Eq. (5). For a point inside the dam, only the heat diffusion [4] and the heat due to the cement hydration (Eq. (1)) intervene, whereas for a superficial point convection (Eq. (2)) and radiation (Eq. (3)) should also be considered.

$$
\left\{\begin{array}{lr}
\frac{\partial Q}{\partial t}=\frac{\partial Q_{D}}{\partial t}+\frac{\partial Q_{H}}{\partial t} & \text { for internal point } \\
\frac{\partial Q}{\partial t}=\frac{\partial Q_{D}}{\partial t}+\frac{\partial Q_{H}}{\partial t}-\frac{\partial Q_{C}}{\partial t}-\frac{\partial Q_{R}}{\partial t} & \text { for superficial point }
\end{array}\right.
$$


The temperature variation in each point of the dam is calculated by considering the heat content for a certain time in that point. The temperature variation is estimated with Eq. (6) and depends of the concrete specific heat $(C)$ and the concrete mass $\left(m_{H}\right)$.

$$
\partial T=\frac{\partial Q}{m_{H} \cdot C}
$$

\subsubsection{Description of model and material properties}

The dam is modelled at a sectional level per length unit (in this case, linear meter) given that one of its dimensions is significantly larger than the other two. The cross-section of the dam was discretized in square elements of $10 \mathrm{~cm}$. The center of gravity of each element is taken as a reference in the calculations, which were performed with finite differences (time intervals sufficiently small to be representative of the real situation were considered). Based on preliminary analyses, the maximum time interval is set to 5 minutes. Consequently, each year requires approximately 105000 time steps. The properties of concrete and the input data of the model are presented in Table 4. The cement content was defined according to the data from the original project of the dam. The other parameters were selected based on previous studies (Amberg 2003, Castilho et al. 2015). These values remain constant during the analysis.

Table 4. Concrete properties and input data for the model.

\begin{tabular}{lc}
\hline \multicolumn{1}{c}{ Parameter } & Value \\
\hline Cement content $\left(\mathrm{kg} \cdot \mathrm{m}^{-3}\right)$ & 285 \\
Specific weight $\left(\mathrm{kg} \cdot \mathrm{m}^{-3}\right)$ & 2500 \\
Specific heat $C\left(\mathrm{~J} \cdot \mathrm{kg}^{-1} \cdot \mathrm{k}^{-1}\right)$ & 1000 \\
Diffusion coefficient $D\left(\mathrm{~m}^{2} \cdot \mathrm{s}^{-1}\right)$ & $1.10 \mathrm{E}-06$ \\
Emissivity $\epsilon(-)$ & 2.75 \\
Convection coefficient $h\left(\mathrm{~W} \cdot \mathrm{m}^{-2} \cdot \mathrm{K}^{-1}\right)$ & 0.9 \\
\hline
\end{tabular}

The construction procedure is defined as casting of consecutive layers. From the bottom to the top of the dam, the elements of the same row are activated as the concrete is cast. According to this, the equations used to calculate the temperature (see previous section) change in each time step. Once cast, the layer is unprotected and exchanges with atmospheric air may occur, besides the diffusion with the bottom and lateral layers. The transfer with the environment stops when the new concrete layer is cast, remaining only the diffusion with the other concrete layers.

\subsubsection{Parametric study}

Given the lack of information regarding the type of cement and construction rate, a parametric study is performed considering different cements and construction rates (see Table 5).

Table 5. Variables of the parametric study.

\begin{tabular}{ll}
\hline \multicolumn{1}{c}{ Parameter } & \multicolumn{1}{c}{ Value } \\
\hline Time between layers $t_{\text {layer }}($ days $)$ & $20(\mathrm{~V} 1)$ and $30(\mathrm{~V} 2)$ \\
Time to cast a layer of $0,1 \mathrm{~m} t_{\text {cast }}(\mathrm{h})$ & $2.4(\mathrm{~V} 1)$ and 3.6 (V2) \\
Maximum energy released $Q_{\max }(\mathrm{kJ} / \mathrm{kg})$ & $150(\mathrm{E} 1), 200(\mathrm{E} 2), 250(\mathrm{E} 3)$ and $300(\mathrm{E} 4)$ \\
Kinetic coefficient $(-)$ & $0.5 \times 10^{-5}(\mathrm{C} 1), 1.0 \times 10^{-5}(\mathrm{C} 2), 1.5 \times 10^{-5}$ \\
& $(\mathrm{C} 3)$ and $2.0 \times 10^{-5}(\mathrm{C} 4)$ \\
\hline
\end{tabular}


Based on the research conducted regarding the construction techniques and technology in the $1950 \mathrm{~s}$, it may be assumed that the concrete layers were cast up to a maximum of $1.5 \mathrm{~m}$ high. Then, the formworks are moved to another block to continue casting. Therefore, a certain time $t_{\text {layer }}$ occurs between the castings of two layers of the same block. The original project of the dam specifies that the concrete of a layer will remain humid for at least 3 weeks after the casting. Based on that, two values of $t_{\text {layer }}$ were defined for the parametric study: 20 days (almost three weeks, according to the curing specifications in the project) and 30 days, when most of the hydration reaction has occurred (these values are also consistent with the construction schedule).

Considering the dimensions of the mixers used at the time of construction, the layer could not have been completed with one mixing. Instead, a layer should be assumed as the sum of several thinner layers of $0.1 \mathrm{~m}$ executed in a time $t_{\text {cast }}$. Two values were also set for these variables: 2.4 hours and 3.6 hours. The values of the parameters considered in the model are included in Table 5. Notice that two situations are evaluated: fast speed (V1) and slow speed (V2).

The other two variables in the parametric study are the maximum energy released $\left(Q_{\max }\right)$ and the kinetics of the energy release of the cement hydration. The first one depends mainly on the composition and the clinker content of the cement, whereas the second is related with the fineness and composition of the clinker. It was mentioned before that the original project of the dam specifies the use of a slow setting cement, however there is no certainty that it was actually employed. In fact, there are evidences that this type of cement was only introduced in the country in the 1970s during the construction of another dam. For the purpose of this study, the values of those variables were defined according to the heat release curves in the literature for several types of slow setting cement (Klemczak and Batog, 2016). The ambient temperature $\left(T_{a}\right)$ and the initial temperature of the concrete before the casting $\left(T_{\text {Hinitial }}\right)$ remain constant along the simulation with a value of $20{ }^{\circ} \mathrm{C}\left(T_{a}\right.$ is always equal to $\left.T_{\text {Hinitial }}\right)$.

\subsection{Evaluation methods: mechanical modelling of the cracking}

Finite element modelling is used in this section to determine if an expansive reaction in the concrete spillway can cause the cracking detected in the diaphragms that support the road bridge. This is an additional method to confirm whether an expansive reaction occurred in the spillway. For that purpose, the finite element software ATENA 4.3.1g (Cervenka 2000) was used. As in the previous thermal modelling, the dam is modelled at a sectional level given that one of its dimensions is significantly larger than the other two. The geometry of the model includes the spillway and a diaphragm. Fig. 6a presents the geometry of the model with the concrete elements and the reinforcement in the pile.
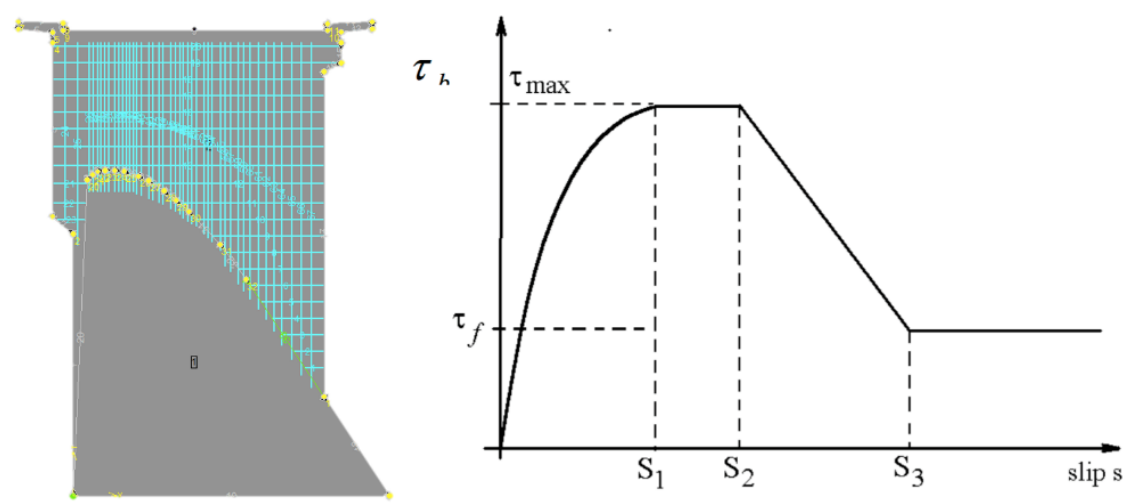

Fig.6 a) Geometry of the model and b) bond model for the reinforcement.

Regarding the materials, records of the quality control are not available. However, mechanical tests performed in the cores drilled from the dam provide average data of the compressive strength 
and modulus of elasticity of 7 cores (see Table 2). Therefore, the compressive strength was set to $27 \mathrm{MPa}$ and the modulus of elasticity to $13.5 \mathrm{GPa}$.

Nonlinear fracture mechanics with the crack band method and smeared cracking is assumed for the behavior of concrete in tension. The behavior of the reinforcement in the piles is defined according to a bilinear model with a value of yield stress of $435 \mathrm{MPa}$. Even though this value might be high for the steel rebars used at the time, its influence in the crack pattern is minor. Adherence was simulated through the bond model included in the Model Code 1990, where $\tau$ is the bond and $\mathrm{s}$ is the slip (see Fig. 6b).

The vertical displacement at the bottom of the spillway and the horizontal displacement in one point at the bottom of the spillway are not allowed. The loads considered in the simulation are the weight of the pile and the spillway and the expansion in the spillway. Given that there is no equipment measuring displacements in the dam, the specific values of the expansion magnitude are unknown. Therefore, typical values associated to ASR were used, namely $0.8 \mathrm{~mm} / \mathrm{m}$ (Thomas et al. 2006, Ben Haha et al. 2007). It should be remarked that the purpose of the simulation is to demonstrate that the expansion can generate the cracking in the pile, rather than obtaining specific values of crack widths. The finite element mesh is formed by a combination of triangular and quadrilateral elements with an average size of $0.10 \mathrm{~m}$.

\section{RESULTS}

\subsection{Microstructural characterization}

\subsubsection{Aggregate identification and analysis}

Sixteen aggregate samples were analyzed by XRD. Among them, 12 aggregate samples were identified as quarzitic rocks since the main crystalline phase was quartz. Feldspar was also detected as a minor phase in eleven of the quarzitic samples, however the low intensity of the reflection at 3.20 $\AA$ did not allow determining the specific type of feldspar (see the XRD patterns in Fig. 7a). In the quarzitic sample - sample Ar-9 -, the feldspars were identified as microcline and albite (see the XRD pattern of sample Ar-9 in Fig. 7b). No other crystalline phases were detected in these aggregate samples.
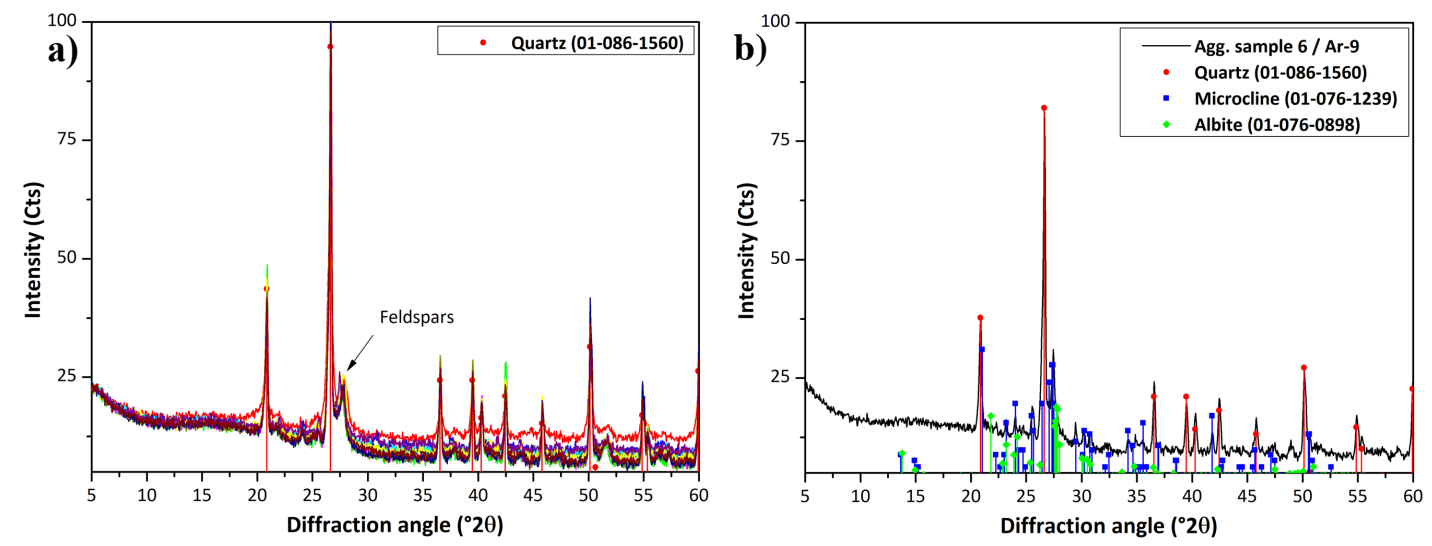

Fig. 7 XRD patterns of the aggregate samples identified as quarzitic rocks: a) samples with unidentified feldspars, and b) sample with presence of microcline and albite.

The other aggregate samples were quarzitic schists with large presence of feldspars (albite) and variable quantities of mica (muscovite). No other crystalline phases were identified. The XRD patterns of the quarzitic schists are shown in Fig. 8. 


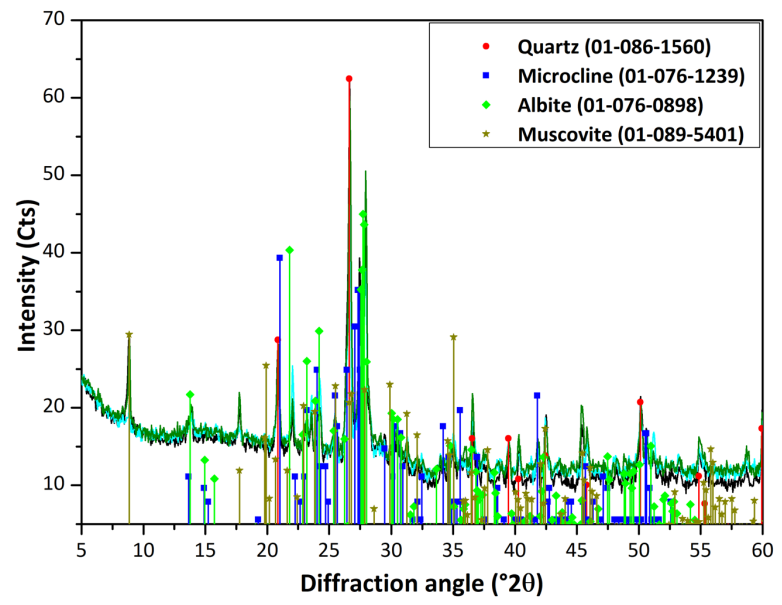

Fig. 8 XRD patterns of the quarzitic schists.

The XRD analyses performed reveal that the aggregate samples were obtained from metamorphic rocks. In particular, twelve of the samples are quartzites and the rest are quartzite schists. The latter present a preferential orientation of the mica minerals with visual foliation, detectable in the visual inspection. No traces of cristobalite were found in any of the samples.

Considering the XRD analyses, five samples were selected for the thin section studies with the optical microscope. This analysis corroborates the presence of quartz, albite and mica. Undulate extinctions, which are characteristic from quarzitic samples with small size crystals and dislocations, were also detected. A fibrous structure that is distinctive of chalcedony with microcrystalline grains was identified in sample Ar-9 (see Fig. 9a). In addition, the feldspars in some of the samples contained clayey phyllosilicates, which is a sign of alteration. Fig.9 shows this alteration as well as the undulate extinction characteristic from quartz.
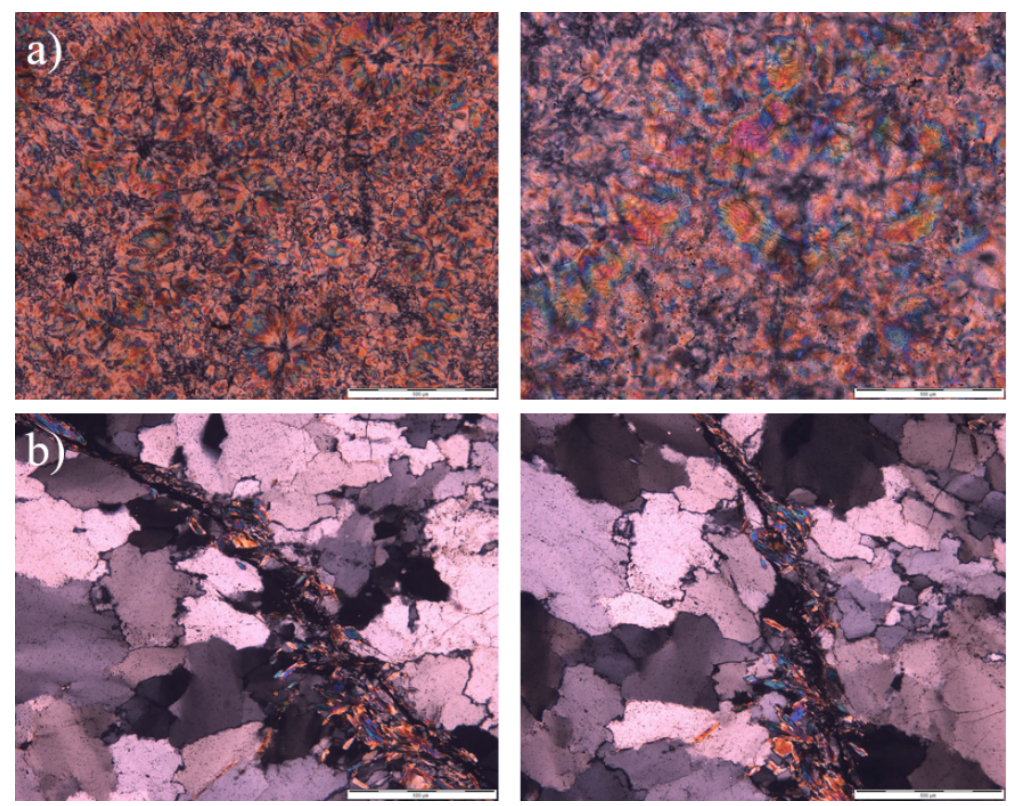

Fig. 9 Thin sections micrographs: a) quarzitic aggregate sample with presence of chalcedony, and $b$ ) undulate extinction characteristic from quartz.

The results reveal that the aggregates used were not suitable for concrete manufacturing since they are prone to react with the alkalis of the cement. Although no amorphous silica was found, other features identified in the quarzitic samples -small grain size, low crystallinity and undulant 
extinctions - are described in the literature as evidences of possible alkali-silica reactivity of the aggregates.

Additionally, physical tests were conducted to determine the reactivity of the aggregates in an accelerated mortar bar testing according to the Argentinian standard IRAM 1674 (1997). The results of expansion measured as the deformation of the bar are presented in Table 6 (Centragolo et al. 2016). The deformation measured at 14 days is in the range $0.1-0.2 \%$, classified as potentially reactive aggregates. Based on the standard recommendations, the test continued up to 32 days which revealed a deformation over $0.15 \%$.

Table 6. Accelerated mortar bar testing to determine reactivity of aggregates.

\begin{tabular}{|l|c|c|c|c|c|c|c|c|c|}
\hline Time (days) & $\mathbf{0}$ & $\mathbf{5}$ & $\mathbf{8}$ & $\mathbf{1 2}$ & $\mathbf{1 4}$ & $\mathbf{1 9}$ & $\mathbf{2 1}$ & $\mathbf{2 6}$ & $\mathbf{3 2}$ \\
\hline Deformation (\%) & 0.000 & 0.047 & 0.082 & 0.102 & 0.118 & 0.126 & 0.133 & 0.147 & 0.157 \\
\hline
\end{tabular}

\subsubsection{Characterization of concrete samples}

The concrete samples from core P1 did not show evidences of degradation (no cracks or reaction rims were found). As seen in Fig. 5a, the concrete is sound with a good distribution of the aggregates and a compact mortar (core P1 was obtained from a pile with no evidences of deterioration). The XRD analysis of a mortar sample confirmed the results of the visual analysis (see Fig. 10).

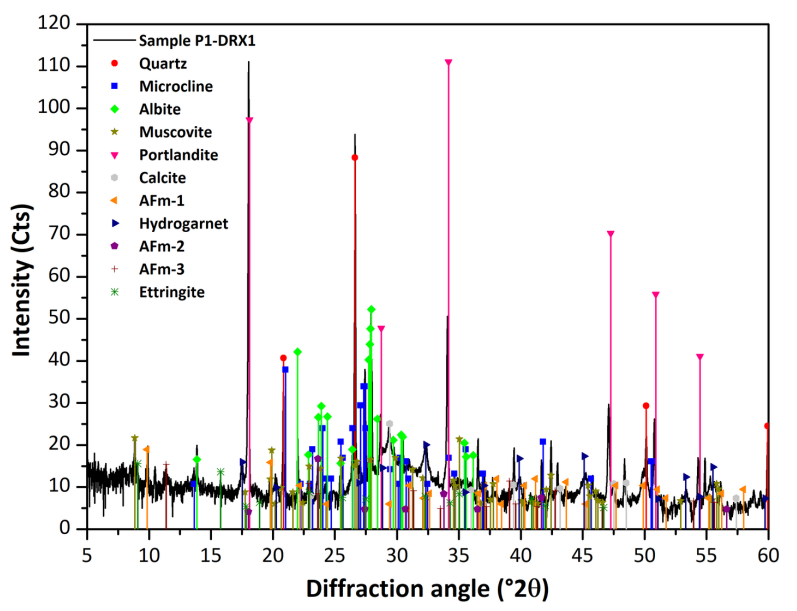

Fig. 10 XRD pattern of a mortar sample from unaltered P1 core

The main crystalline phases identified were related to the aggregates (quartz, microcline, albite and muscovite) and to the cement hydration. Portlandite presented a very intense reflection that may be related with the use of a cement with high contents of clinker during the construction of the dam. The presence of monosulphoaluminate phases - namely Afm-1, 2, and 3, related with kuzelite, hidrocalumite, and ye'elemite (Balonis, 2010) - and the low intensity of the ettringite are a sign of the normal conversion of Aft phases into Afm over the time.

The other concrete samples - M1, T1, and T2 - exhibit cracks along the cement paste and the aggregates as well as white precipitates inside pores. The XRD patterns of the mortar samples presented similar features regarding the crystalline phases in the altered and in the sound samples (see Fig. 11). Besides the reflections from the aggregates, the high intensity of the ettringite reflections (compared to those found in P1) indicate that the concrete samples contain significant amount of ettringite that has not been transformed into Afm phases. Furthermore, the peaks related to portlandite present low intensity. Lastly, okenite was found as a minor phase in some of the mortar samples. This product has been identified by other authors (Dähn et al., 2016) as a crystalline phase of the ASR 

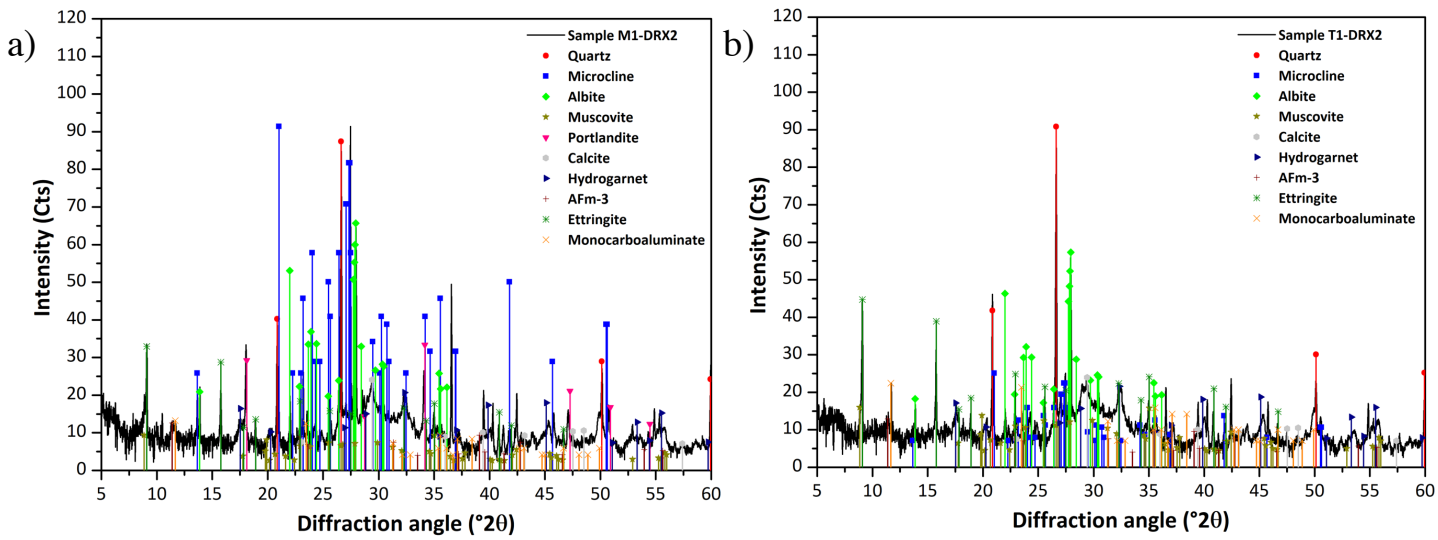

Fig. 11 XRD patterns of mortar samples from degraded concrete samples: a) M1, and b) T1.

Products of the ASR reaction were found in the mortar samples from M1. Fig.12a shows SEM images with massive formations of ASR gel and the corresponding EDX analysis. The relative intensities of potassium and calcium peaks (see EDX analysis) reveal an advanced stage of the ASR. As the reaction progresses, the pore solution and the ASR gel exchange potassium and calcium ions (Godart et al., 2013).
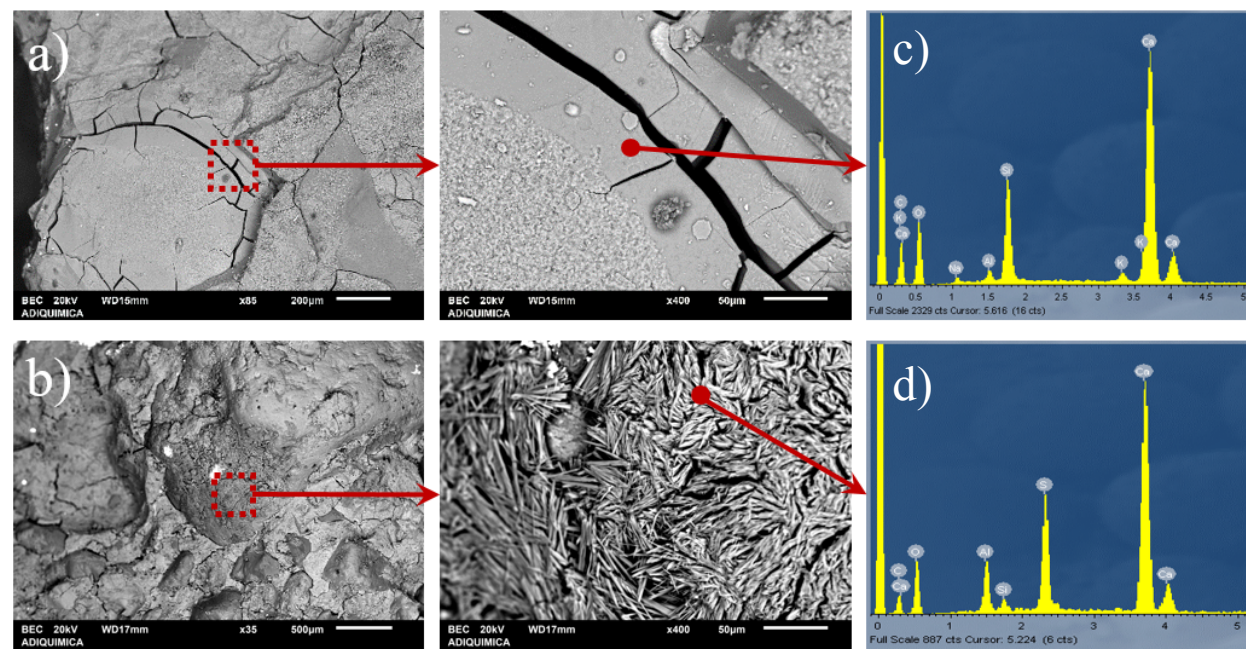

Fig. 12 SEM images of mortar samples: a) ASR products in M1 and b) ettringite in T1, c) EDX of M1 and d) EDX of T1.

The ASR gel appeared in all the samples and, in some cases, it also appeared combined with massive precipitacion of ettringtie (samples from cores $\mathrm{T} 1$ and T2). The ettringite was well distributed into the cement paste and precipitated in pores. Fig. $12 \mathrm{~b}$ shows an example of ettringite precipitation in the cement paste, confirmed by the EDX analysis (the ettringite was widely dispersed in the surface of the samples). This was detected in samples from cores M1, T1 and T2 together with monosulphoaluminate phases. In some of the samples, the ettringite needles detected are fossilized by different neoformed products whose morphology and composition suggest a product of the ASR in an initial stage of the reaction (see Fig.13).

The microstructural characterization of the mortar samples shows different degradation phenomena. The high content of ettringite shown in the XRD analyses and the morphology of the ettringite detected as well as its wide dispersion in the cementitious matrix indicate that the cause might be a delayed ettringite formation (DEF). Previous studies have reported similar SEM images of concrete samples with DEF (Sahu and Thaulow, 2004; Escadeillas et al., 2007). 

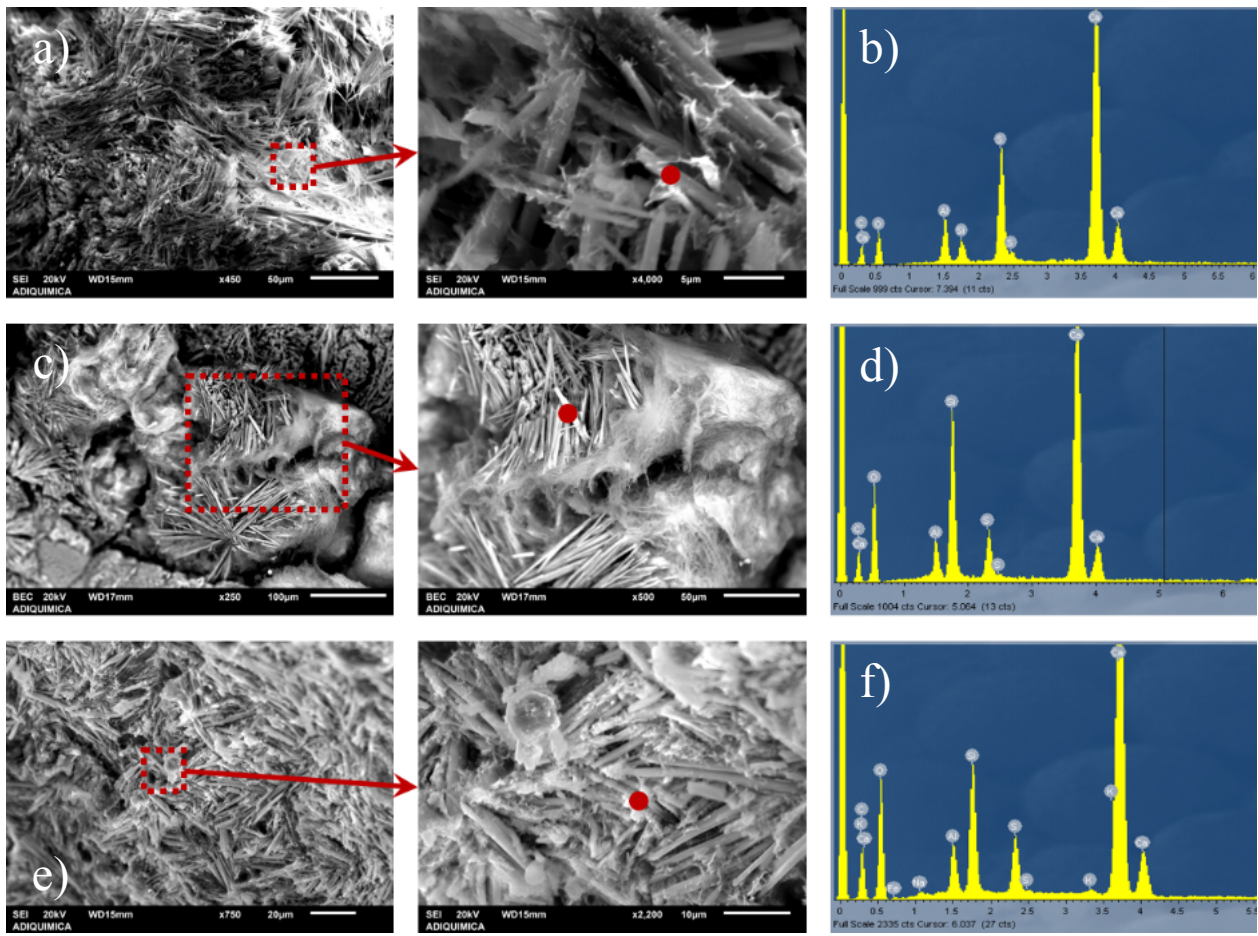

Fig. 13 Fossilization of ettringite by ASR products in mortar samples from a) M1, c) T1 and e) T2 and EDX analyses of b) M1, d) T1 and f) E1.

The presence of DEF may be justified by the use of a cement with high content of clinker, as suggested by the significant amounts of Portlandite in the mortar samples of P1. As previously mentioned, DEF occurs when the temperature of concrete during construction or curing exceeds $70^{\circ} \mathrm{C}$ (Taylor et al., 2001; Collepardi, 2003). Furthermore, the hydrogarnet detected in the XRD analyses of the mortar samples has been related by some authors (Paul and Glasser, 2000) with a long curing process of concrete at high temperatures. Furthermore, the fossilization of ettringite by the ASR products justify that ettringite precipitation must have occurred in early stages of the service life of the dam.

\subsection{Thermal modelling}

The results of the thermal modelling are presented in Fig. 14 and Fig. 15 by plotting the maximum temperatures reached in the cross section of the dam assuming construction rates V1 and V2, respectively (see details for construction rates in Table 5).

A general overview of both figures, reveals that the highest temperature occurs in the center of the different layers. Such outcome is reasonable since the points close to the surface are exposed to the heat transfer with adjacent layers or the environment. 


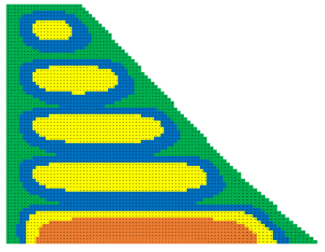

a) V1_E1_C1

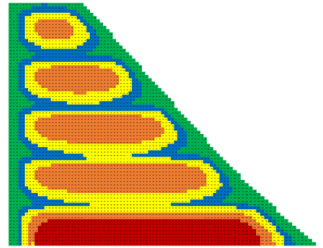

e) V1_E2_C1

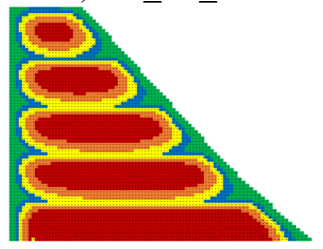

i) V1_E3_C1

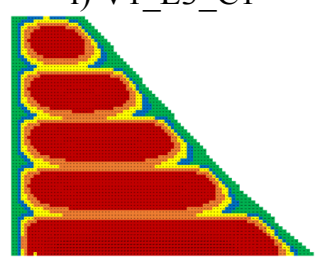

m) V1_E4_C1

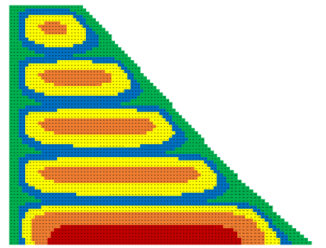

b) V1_E1_C2

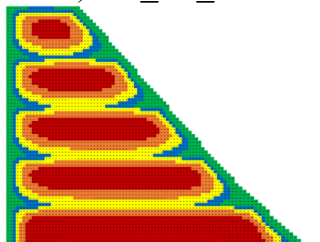

f) V1_E2_C2

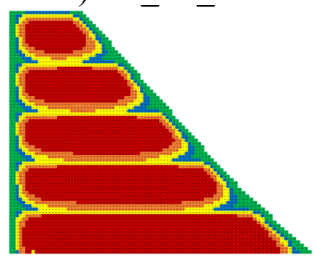

j) V1_E3_C2

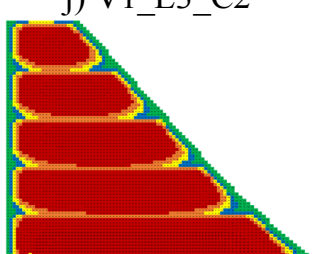

n) V1_E4_C2

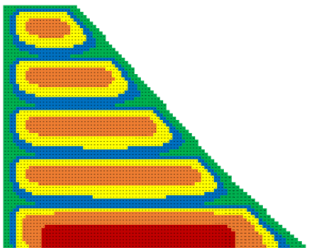

c) V1 E1 C3

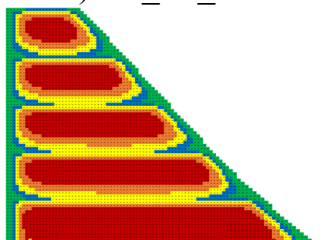

g) V1_E2_C3

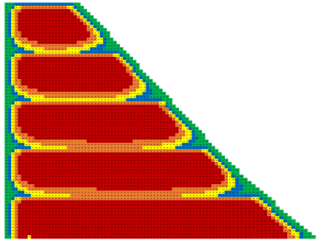

k) V1 E3 C3

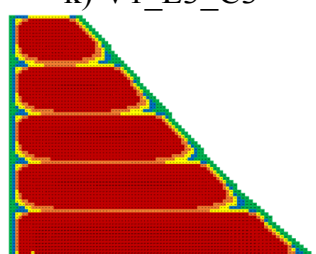

o) V1_E4_C3

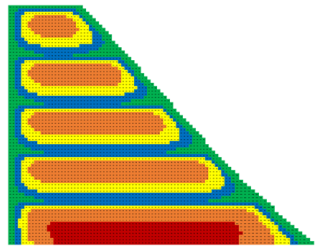

d) V1_E1_C4

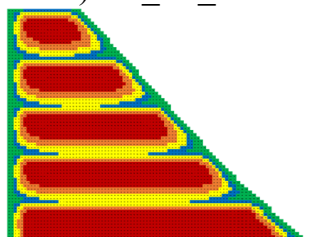

h) V1_E2_C4

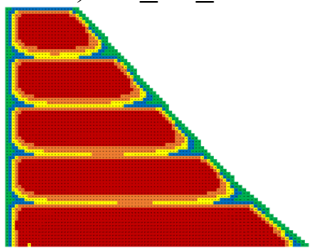

1) V1_E3_C4

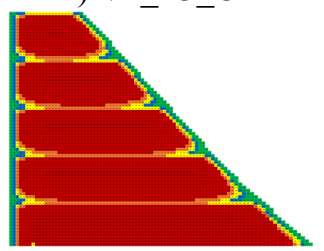

p) V1_E4_C4

\section{$20-40{ }^{\circ} \mathrm{C} \quad 40-50{ }^{\circ} \mathrm{C} \quad 50-60{ }^{\circ} \mathrm{C} \quad 60-70{ }^{\circ} \mathrm{C}$}

Fig. 14 Maximum temperature reached in each point for construction rate V1.

The figures also reveal that in some cases the temperatures reach values over $70^{\circ} \mathrm{C}$, even in points close to the surface of the dam, which is consistent with the DEF.

If equivalent scenarios are compared for both V1 (see Fig. 14) and V2 (see Fig. 15), a similar distribution is observed. The construction ratio V2 leads to temperatures that are between $1{ }^{\circ} \mathrm{C}$ and $3^{\circ} \mathrm{C}$ lower than for construction ratio $\mathrm{V} 1$; nevertheless, the center of the layer still reaches temperatures higher than $70^{\circ} \mathrm{C}$.

In the scenarios of Fig. 14 and Fig. 15 with the highest temperatures, an expansion of the central area due to the DEF is highly probable. This increment of volume leads to field of stresses consisting in compression in the center of the layer and tension in the upstream and downstream faces. In the cases where the tensile strength of the concrete is exceeded, horizontal cracking appears. 


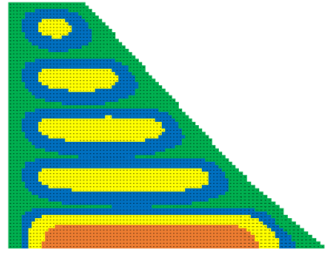

a) V2_E1_C1

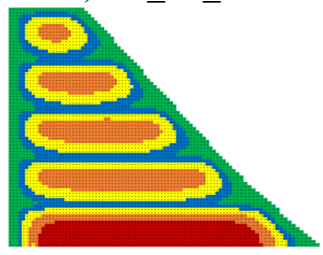

e) V2 E2 C1

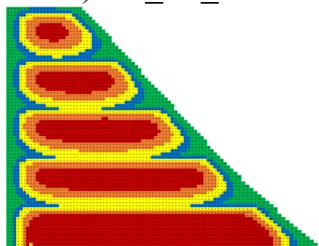

i) V2_E3_C1

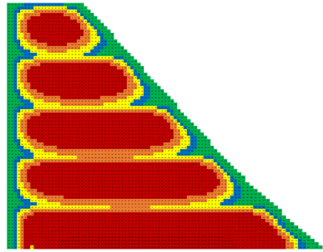

m) V2_E4_C1

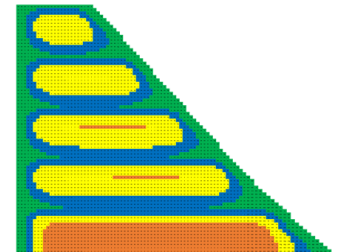

b) V2_E1_C2

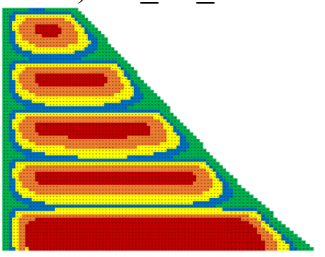

f) $\mathrm{V} 2-\mathrm{E} 2-\mathrm{C} 2$

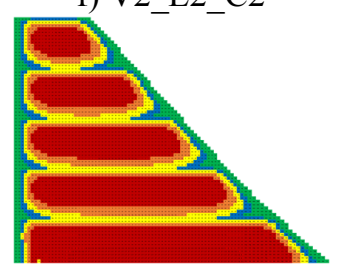

j) V2_E3_C2

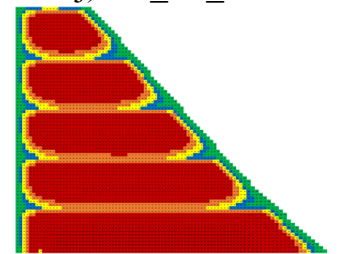

n) V2_E4_C2

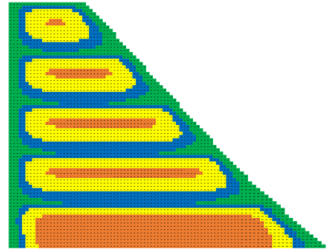

c) V2_E1_C3

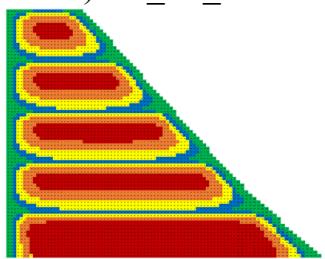

g) V2_E2_C3

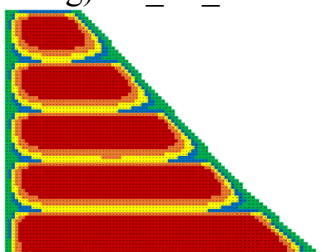

k) V2 E3 C3

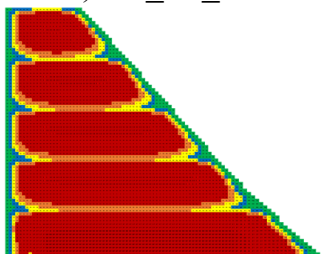

o) V2_E4_C3

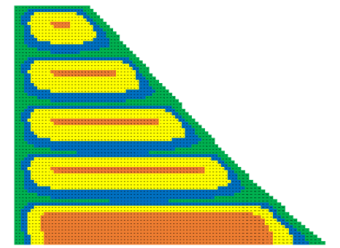

d) V2_E1_C4

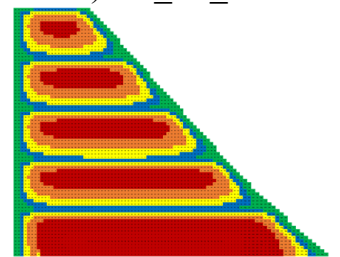

h) V2_E2_C4

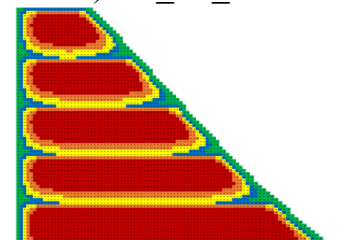

1) V2_E3_C4

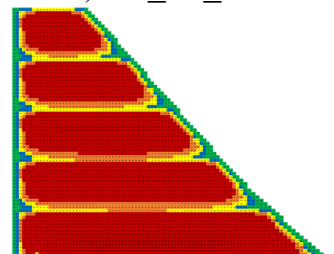

p) V2_E4_C4

\section{$20-40{ }^{\circ} \mathrm{C} \quad 40-50{ }^{\circ} \mathrm{C} \quad 50-60{ }^{\circ} \mathrm{C} \quad 60-70{ }^{\circ} \mathrm{C}$}

Fig. 15 Maximum temperature reached in each point for construction rate V2.

Fig. 16 presents the influence of the maximum hydration energy of the cement in the maximum temperature for scenarios with a construction rate $\mathrm{V} 1$ and hydration kinetics $\mathrm{C} 1$ and $\mathrm{C} 4$ at different heights of the dam $(0.75 \mathrm{~m}, 2.25 \mathrm{~m}, 3.75 \mathrm{~m}$ and $5.25 \mathrm{~m})$. All cases correspond to points located in the center of the layers. Notice that each graph is associated to a hydration kinetic $(\mathrm{C} 1$, $\mathrm{C} 2, \mathrm{C} 3$ and $\mathrm{C} 4)$.

The curves exhibit a maximum energy released threshold value above which the temperature in the center of the layers exceeds $70^{\circ} \mathrm{C}$. This threshold value depends on the hydration kinetics, however for the cases studied in Fig.16 it ranges from $160 \mathrm{~kJ} / \mathrm{kg}$ to $225 \mathrm{~kJ} / \mathrm{kg}$. These values correspond to the values of energy released of current low heat cements (Klemczak and Batog, 2016). If a slow setting cement was used at the time of construction, which is highly unlikely due to the information received regarding the introduction of this type of cement in the country (see section 2.2), the hydration heat would not have been lower than $200 \mathrm{~kJ} / \mathrm{kg}$. Therefore, it is highly probable that the temperature inside the dam exceeded $70^{\circ} \mathrm{C}$ at some point. Consequently, even though thermal cracking might have contributed to the horizontal cracks in the spillway, DEF is a plausible cause of the cracking in the spillway observed few years after the construction of the dam. 

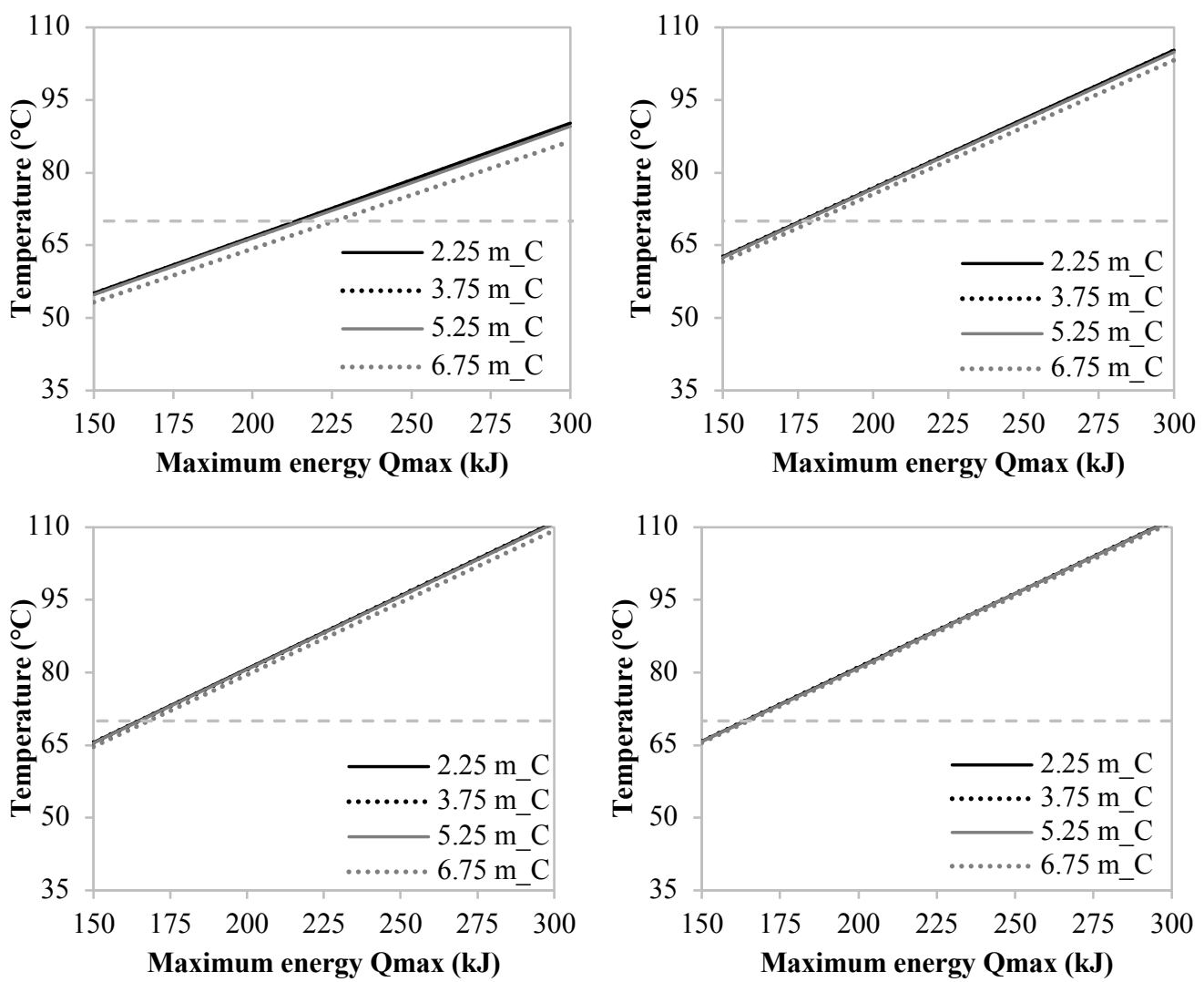

Fig. 16 Influence of the maximum energy released in the hydration in the maximum temperature reached at the center of different layers (at different heights).

\subsection{Mechanical modelling of the cracking}

Fig. 17a shows the crack pattern observed in the diaphragms. This pattern suggests that the cause of the cracks may be a volumetric expansion in the spillway. Fig. 17b illustrates the tension stresses that would be generated in the diaphragms if an expansion did occur in the spillway. If those stresses reached the tensile strength of concrete, the cracks would appear perpendicularly to the direction of the tension, as observed in the real crack pattern of Fig. 17a.
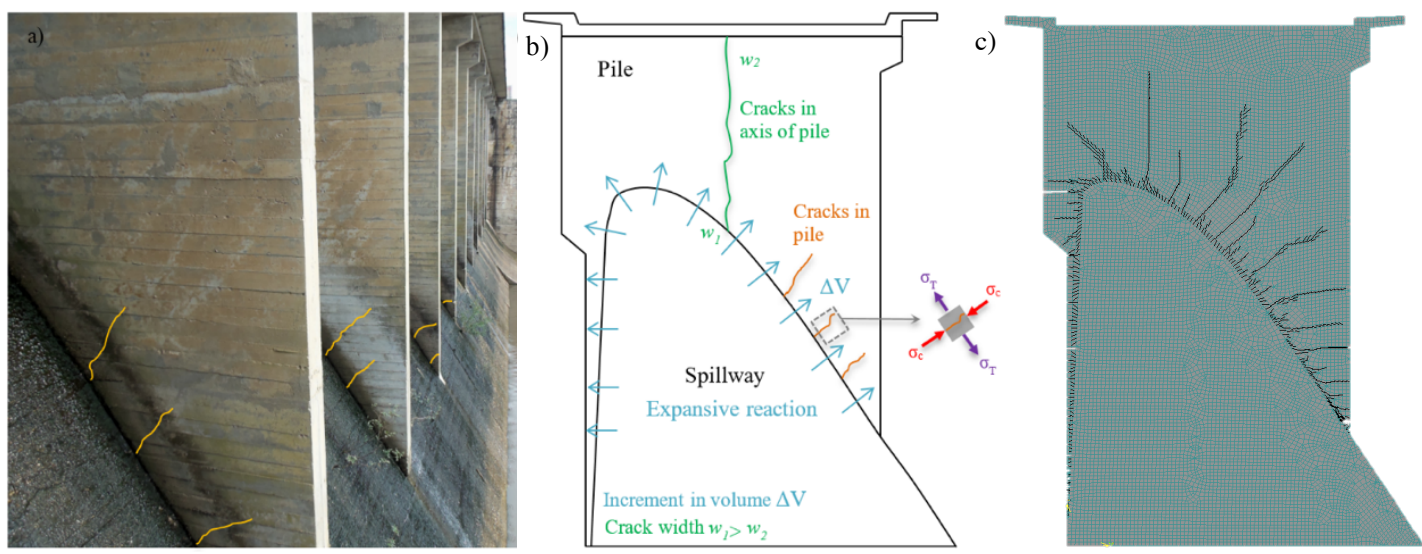

Fig.17 a) real crack pattern, b) stresses in the diaphragm and c) crack pattern of the model.

The crack pattern yielded by the model and generated as a result of the expansion imposed in the spillway is presented in Fig. 17c. In the model, the cracks begin at the spillway and develop 
towards the diaphragm (see Fig. 17c), which is consistent with the real pattern shown in Fig. 17a. Even though the modelling is mainly qualitative due to the lack of real data, the results confirm the hypothesis that the cracking in the diaphragm is caused by an expansion in the spillway.

Notice that the vertical crack observed in several diaphragms of the bridge is also due to the expansive reaction. However, its development is governed by the presence of a construction joint that is a weak plane and is also more susceptible to cracking (the joint in the diaphragm was not represented in the model and, therefore, no crack develops in the axis).

\section{CONCLUSIONS}

A comprehensive diagnosis of a concrete dam with significant cracking and other signs of deterioration that suggest the presence of expansive phenomena in the concrete was presented. The causes of the damage were identified by performing a microstructural analysis involving different techniques. Moreover, a thermal modelling of the construction procedure and a mechanical modelling of the cracking through FE of were developed in order to further study the plausibility of the hypotheses. Subsequently, the most relevant findings are presented:

- The research conducted among the local technicians indicates that slow setting cements were introduced in the country after the construction of the dam studied in this paper, namely 20 years later.

- The physical test performed on the aggregates used in the construction confirmed their potential alkali-silica reactivity as well as the microstructural analysis that showed features described in the literature as evidences of possible reactivity (specifically small grain size, low crystallinity and undulant extinctions).

- The mortar samples presented ASR products at different stages of the reaction and ettringite. The morphology and distribution of the ettringite in the cementitious matrix suggests that its origin may be due to a DEF. Neoformed products of the ASR were found fossilizing the ettringite, which ties in with a DEF early after the construction of the dam and a subsequent ASR.

- The thermal modelling of the dam revealed that it is highly probable that the temperatures inside the concrete exceeded $70^{\circ} \mathrm{C}$ during the construction, which may lead to DEF and the horizontal cracks in the spillway. However, the study does not discard that thermal cracking might have also occurred.

- The modelling through finite elements showed that a volumetric expansion in the spillway generates tension stresses in the diaphragms of the bridge which leads to cracking with a pattern that is consistent with the real crack pattern observed.

The findings presented above indicate that the damage observed in the dam was caused by an early DEF due to high temperatures of the concrete during the construction and a subsequent ASR caused by the use of alkali-silica reactive aggregates. The fact that different methods converge towards the same hypothesis strengthens the diagnosis presented.

\section{ACKNOWLEDGEMENTS}

The authors acknowledge the economic support provided by the Spanish Ministry of Science and Innovation through the project BIA2013-49106-C2-1-R and the collaboration project with Universidad de la República (Uruguay). The authors thank Professor Servando Chinchón and Dr. Servando Chinchón-Payá for their collaboration in the microstructural analyses of this study. 


\section{REFERENCES}

ACI. "ACI 214-R11 Guide to Evaluation of Strength Test Results of Concrete". American Concrete Institute. 2011. Farmington Hills, MI, USA.

Ayora, C., Chinchón, J.S., Aguado, A., Guirado, F., "Weathering of Iron Sulfides and Concrete Alteration: Thermodynamic Model and Observation in Dams from Central Pyrenees, Spain”. Cem. Concr. Res., vol. 8, no. 4, 1998, p. 591-603. DOI: 10.1016/S0008-8846(98)00019-2.

Amberg, F. "Thermal Analysis of a RCC Dam during Construction". $7^{\text {th }}$ ICOLD Benchmark Workshop on Numerical Analysis of Dams. 24-26 Sept. 2003, Bucarest (Romania).

Balonis, M. "The influence of inorganic chemical accelerators and corrosion inhibitors on the mineralogy of hydrated Portland cement systems". Master Thesis, University of Aberdeen, Aberdeen 2010.

Ben Haha, M., Gallucci, E., Guidoum, A., Scrivener, K.L. "Relation of expansión due to alkali silica reaction to the degree of reaction measured by SEM image analysis". Cem. Concr. Res., vol. 37, 2007, p. 1206-1214. DOI: 10.1016/j.cemconres.2007.04.016.

Blanco, A., de la Fuente, A., Cavalaro, S.H.P., Aguado, A., "A century of sand-cement: durability of the concrete in the Camarasa dam". J. Perform. Constr. Fac., vol. 30, no. 4, 2016, p. 04015083-1 - 0401508310. DOI: 10.1061/(ASCE)CF.1943-5509.0000823

Castilho, E.M., Schclar Leitão, N., Tiago, C. "Thermal Analysis of Concrete Dams during Construction Phase”. Second International Dam World Conference. 21-24 Apr. 2015. Lisbon (Portugal).

Centragolo, G., Segura, L., Auline, A., Morquio A. "Case Study: Diagnosis of Expansive Processes of Concrete". XXXVII South American Workshop on Structural Engineering. November 2-4, 2016, Asuncion, Paraguay (In Spanish).

Cervenka, V., "Simulating a response". Concr. Eng. Int., vol. 4, no. 4, 2000; p. 45-49.

Chinchón, J.S., Ayora, C., Aguado, A., Guirado, F., "Influence of Weathering of Iron Sulphides Contained in Aggregates on Concrete. Durability". Cem. Concr. Res., vol. 25, no. 5, 1995, p. 1264-1272. DOI: 10.1016/0008-8846(95)00119-W.

Chinchón-Payá, S., Aguado, A., Coloma F., Chinchón, J.S., "Study of aggregate samples with iron sulphides trough micro X-Ray Fluorescence ( $\mu \mathrm{XRF}$ ) and X-ray Photoelectron Spectroscopy (XPS)". Mater. Struct., vol. 48, no. 5, 2015, p. 1285-1290. DOI: 10.1617/s11527-013-0233-z.

Collepardi, M. (2003) A state-of-the-art review on delayed ettringite attack on concrete. Cement and Concrete Composites, 25, pp. 401-407.

Dähn, R., Arakcheeva, A., Schaub, Ph., Pattison, P., Chapuis, G., Grolimund, D., Wieland, E., Leemann, A. (2016) Application of micro X-ray diffraction to investigate the reaction products formed by the alkalisilica reaction in concrete structures. Cement and Concrete Research, 79, pp. 49-56.

Diamond, S. "Delayed ettringite formation - Processes and problems". Cem. Concr. Comp., vol. 18, 1996, p. 205-215. DOI: 10.1016/0958-9465(96)00017-0.

Escadeillas G., Aubert, J-E., Segerer, M., Prince, W. (2007) Some factors affecting delayed ettringite formation in heat-cured mortars. Cement and Concrete Research, 37 (10), pp. 1445-1452.

Godart, B., de Rooij, M., Wood, J. G. M. (2013) Guide to Diagnosis and Appraisal of AAR Damage to Concrete in Structures - Part 1 Diagnosis (AAR 6.1). Springer Netherlands, pp. 63-64.

Grattan-Bellew, P.E., Chan, G. "Comparison of the morphology of alkali-silica gel formed in limestones in concrete affected by the so-called alkali-carbonate reaction (ACR) and alkali-silica reaction (ASR)". Cem. Concr. Res., vol. 47, 2013, p. 51-54. DOI: 10.1016/j.cemconres.2013.01.013

Hobbs, D. W., ASR in concrete, Michigan, Telford, 1988.

Kennerly, R. A., "Ettringite Formation in Dam Gallery”. ACI Journal, vol. 62, 1965, p. 559-576.

Klemczak, B., Baton, M, "Heat of hydration of low-clinker cements". J. Therm. Anal. Calorim., vol. 123, no. 2, p. 1351-1360.

IRAM 1674. Agregados. Determinación de la reactividad alcalina potencial. Método acelerado de la barra de mortero. Instituto Argentino de Normalización y Certificación, Buenos Aires, Argentina (in Spanish). 
Na, O., Yunping, X., Ou, E. Saouma, V. "The effects of alkali-silica reaction on the mechanical properties of concretes with three different types of reactive aggregate”. Struct. Concrete, vol. 17, no.1, 2016, p- 7483.10.1002/suco.201400062.

Oliveira, I., Cavalaro, S.H.P., Aguado, A., "New kinetic model to quantify the internal sulfate attack in concrete". Cem. Concr. Res., vol. 43, no. 1, 2013a, p. 95-106. DOI: 10.1016/j.cemconres.2012.09.010.

Oliveira, I., Cavalaro, S.H.P., Aguado, A. "New unreacted-core model to predict pyrrhotite oxidation in concrete dams". J. Mater. Civil Eng., vol. 25, no. 3, 2013b, 372-381. DOI: 10.1061/(ASCE)MT.19435533.000053 .

Oliveira, I., Cavalaro, S.H.P., Aguado, A., "Evolution of pyrrhotite oxidation in aggregates for concrete". Mater. Construcc., vol. 64, no. 316, 2014. DOI: 10.3989/mc.2014.08413.

Paul, M., Glasser, F. P. (2000) Impact of prolonged warm $\left(85^{\circ} \mathrm{C}\right)$ moist cure on Portland cement paste. Cement and Concrete Research, 30, pp. 1869-1877.

Ramyar, K., Topal, A., Andiç, Ö. "Effects of aggregate size and angularity on alkali-silica reaction”. Cem. Concr. Res., vol. 35, 2005, p. 2165-2169.

Rodrigues, A., Duchesne, J., Fournier, B. "A new accelerated mortar bar test to assess the potential deleterious effect of sulfide-bearing aggregate in concrete". Cem. Concr. Res., vol. 73, 2015, 96-110. DOI: 10.1016/j.cemconres.2015.02.012.

Rodrigues, A., Duchesne, J., Fournier, B. "Quantitative assessment of the oxidation potential of sulfidebearing aggregates in concrete using an oxygen consumption test”. Cem. Concr. Comp., vol. 67, 2016, 93100. DOI: 10.1016/j.cemconcomp.2016.01.003.

Šachlová, S., Pertold, Z., Št’astná, A., Míčka, T., "Factors affecting DEF and ASR in the concrete dam at Vrané nad Vlatavou". International Journal of Research in Engineering and Technology, vol. 3, no. 13, 2014, p. 57-62.

Sanchez, L.F.M., Fournier, B., Jolin, M., Mitchell, D., Bastien, J. “Overall assessment of Alkali-Aggregate Reaction (AAR) in concretes presenting different strengths and incorporating a wide range of reactive aggregate types and natures". Cem. Concr. Res., vol. 93, 2017, p. 17-31. DOI: 10.1016/j.cemconres.2016.12.001.

Sahu, S. and Thaulow, N. (2004) Delayed ettringite formation in Swedish concrete railroad ties. Cement and Concrete Research, 34, pp. 1675-1681.

Schmidt, T., Leemann, A., Gallucci, E., Scrivener, K.L. "Microstructural investigations of iron sulfide degradation in concrete". In: Int. Baustofftagung (IBAUSIL), Weimar, Germany, 2009, pp. 23-26.

Scrivener, K. L., Taylor, H. F. W., "Delayed ettringite formation: a microstructural and microanalytical analysis”. Adv. Cem. Res., vol. 5, no. 20, 1993, p.139-146.

Stanton, T. E., "Expansion of concrete through reaction between cement and aggregate". Transactions of the American Society of Civil Engineers, 107(1), 1942, p. 57-84.

Stukovnik, P., Princic, T., Pejovnik, R.S., Bokan Bosiljkov, V. "Alkali-carbonate reaction in concrete and its implications for a high rate of long-term compressive strength increase". Constr. Build. Mater., vol. 50, 2014 p. 699-709. DOI: 10.1016/j.conbuildmat.2013.10.007.

Taylor, H. F. W., Famy, C., Scrivener, K. L., "Delayed ettringite formation”, Cem. Concr. Res., vol. 31, no. 5, 2001, p. 683-693. DOI: 10.1016/S0008-8846(01)00466-5.

Thomas, M., Fournier, B., Folliard, K., Ideker, J., Shehata, M. "Test methods for evaluating preventive measures for controlling expansion due to alkali-silica reaction in concrete". Cem. Concr. Res. Vol. 36, 2006, p. 1842-1856. DOI: 10.1016/j.cemconres.2006.01.014.

UNIT. "UNIT-NM 69:1998 Hormigón. Extracción, preparación y ensayo de testigos de estructuras de hormigón”. Instituto Uruguayo de Normas Técnicas. 1998. Montevideo, Uruguay (in Spanish).

Zhang, C., Wang, A., Tang, M., Wu, B., Zhang, N. "Influence of aggregate size and aggregate size grading on ASR expansion”. Cem. Concr. Res., vol. 29, 1999, p. 1393-1396. DOI: 10.1016/S0008-8846(99)00099$\mathrm{X}$. 